\title{
Magnesium Therapy in Pre-eclampsia Prolongs Analgesia Following Spinal Anaesthesia with Fentanyl and Bupivacaine: An Observational Study
}

\author{
Tülay Özkan Seyhan ${ }^{1}$, Olgaç Bezen ${ }^{2}$, Mukadder Orhan Sungur ${ }^{1}$, İbrahim Kalelioğlu ${ }^{3}$, \\ Meltem Karadeniz ${ }^{1}$, Kemalettin Koltka ${ }^{1}$ \\ 'Department of Anesthesiology, İstanbul University İstanbul Faculty of Medicine, İstanbul, Turkey \\ ${ }^{2}$ Department of Anesthesiology, İstanbul Bilim University Faculty of Medicine, İstanbul, Turkey \\ ${ }^{3}$ Department of Obstetrics and Gynecology, İstanbul University İstanbul Faculty of Medicine, İstanbul, Turkey
}

Background: Magnesium has anti-nociceptive effects and potentiates opioid analgesia following its systemic and neuraxial administration. However, there is no study evaluating the effects of intravenous (IV) magnesium sulphate $\left(\mathrm{MgSO}_{4}\right)$ therapy on spinal anaesthesia characteristics in severely pre-eclamptic patients.

Aims: The aim of this study was to compare spinal anaesthesia characteristics in severely pre-eclamptic parturients treated with $\mathrm{MgSO}_{4}$ and healthy preterm parturients undergoing caesarean section. Thus, our primary outcome was regarded as the time to first analgesic request following spinal anaesthesia.

Study Design: Case-control Study.

Methods: Following approval of Institutional Clinical Research Ethics Committee and informed consent of the patients, 44 parturients undergoing caesarean section with spinal anaesthesia were enrolled in the study in two groups: Healthy preterm parturients (Group C) and severely pre-eclamptic parturients with IV MgSO4 therapy (Group $\mathrm{Mg}$ ). Following blood and cerebrospinal fluid (CSF) sampling, spinal anaesthesia was induced with $9 \mathrm{mg}$ hyperbaric bupivacaine and
$20 \mu \mathrm{g}$ fentanyl. Serum and CSF magnesium levels, onset of sensory block at T4 level, highest sensory block level, motor block characteristics, time to first analgesic request, maternal haemodynamics as well as side effects were evaluated.

Results: Blood and CSF magnesium levels were higher in Group Mg. Sensory block onset at T4 were 257.1 \pm 77.5 and $194.5 \pm 80.1 \mathrm{sec}$ in Group $\mathrm{C}$ and $\mathrm{Mg}$ respectively $(\mathrm{p}=0.015)$. Time to first postoperative analgesic request was significantly prolonged in Group $\mathrm{Mg}$ than in Group C (246.1 \pm 52.8 and $137.4 \pm 30.5 \mathrm{~min}$, respectively, $\mathrm{p}<0.001$; with a mean difference of $108.6 \mathrm{~min}$ and $95 \%$ CI between 81.6 and 135.7). Side effects were similar in both groups. Group $\mathrm{C}$ required significantly more fluids.

Conclusion: Treatment with $\mathrm{IV} \mathrm{MgSO}_{4}$ in severe pre-eclamptic parturients significantly prolonged the time to first analgesic request compared to healthy preterm parturients, which might be attributed to the opioid potentiation of magnesium.

(Balkan Med J 2014;31:143-8).

Key Words: Caesarean section, magnesium sulphate, pre-eclampsia, spinal anaesthesia
Magnesium is an essential part of therapy in severe preeclampsia for eclampsia prophylaxis. Besides its anticonvulsant and neuroprotective properties, this bivalent cation is an $\mathrm{N}$-methyl-D-aspartate (NMDA) receptor antagonist and is frequently cited in the anaesthesia literature for its anti-nociceptive effects with conflicting results $(1,2)$. In non-obstetric populations, several studies have reported intravenous (IV) magnesium administration to be beneficial for postoperative analgesia following neuraxial anaesthesia (3-6), whereas one study could not demonstrate this effect (7). This controversy can in part originate from the fact that, in healthy humans, the passage of magnesium to cerebrospinal fluid (CSF) is lim- ited when administered intravenously (1). However, this may not be true for pre-eclamptic patients as vascular permeability alterations in pre-eclamptic patients may change the transfer of magnesium to the CSF (8). There are only a few studies exploring magnesium passage to CSF in the presence of preeclampsia (9-11). Indeed, in pre-eclamptic parturients receiving IV magnesium sulphate $\left(\mathrm{MgSO}_{4}\right)$, Thurnau et al. (9) found small but significant increases in CSF magnesium levels.

Neuraxial anaesthesia, if not contraindicated, has recently been shown to be the method of choice in pre-eclamptic parturients for caesarean delivery (12). Magnesium treatment in severely pre-eclamptic patients may also offer an advantage 
for anti-nociception following neuraxial anaesthesia; however, there is no study exploring this effect. In this prospective observational study, we tested the hypothesis that IV $\mathrm{MgSO}_{4}$ therapy in severe pre-eclampsia would prolong the time to first analgesic request following fentanyl and bupivacaine spinal anaesthesia compared to healthy non-pre-eclamptic preterm parturients.

\section{MATERIAL AND METHODS}

According to our institutional protocol, all severely pre-eclamptic patients are admitted to the obstetric unit once diagnosed, as per the guidelines (13), and antihypertensive medication with 24-hour IV $\mathrm{MgSO}_{4}$ treatment is started. In patients with gestational age $<34$ weeks, as long as the foetus and the mother are stable, delivery is delayed to achieve foetal lung maturity with conservative treatment. In patients with gestational age $\geq 34$ weeks, delivery is planned after stabilisation of the mother. $\mathrm{MgSO}_{4}$ therapy includes a bolus of $4.5 \mathrm{~g}$ $\mathrm{MgSO}_{4}$ given over 10-15 minutes in the labour ward followed by an infusion of $2 \mathrm{~g} / \mathrm{h}$ until transfer to the operating room.

After obtaining approval of Clinical Research Ethics Committee of our institution and informed consent from participants, 44 parturients receiving antenatal care at our institution and undergoing caesarean section with spinal anaesthesia were enrolled in the study in two groups: Healthy preterm parturients with gestational age $<37$ weeks (Group C) and severely pre-eclamptic patients with ongoing $\mathrm{IV} \mathrm{MgSO}_{4}$ therapy (Group Mg). Patients in active labour or in need of emergent caesarean section, contraindication or unwillingness to undergo regional anaesthesia, patients with eclampsia, patients with hemolysis, elevated liver enzymes and low platelets (HELLP syndrome) or renal and hepatic involvement of pre-eclampsia, spinal block failure, blood-stained CSF sample or patients with haemolysis in their blood sample were excluded from the study.

The team collecting intraoperative and postoperative data was blinded to the study. Parturients' demographic data (weight, height, age) and gestational weeks were noted. Preoperatively, patients were encouraged to report the request for analgesics postoperatively when needed. All patients received $500 \mathrm{~mL}$ of lactated Ringer solution in the operating room prior to lumbar puncture. Further fluid was restricted to a minimum rate to retain vein patency until spinal injection. Lumbar puncture was performed with $25 \mathrm{G}$ Quincke tip needle (B. Braun, Melsungen AG, Germany) in the sitting position at L3-4 or L4-5 level using a midline approach. Before intrathecal drug administration, $0.5 \mathrm{~mL}$ of CSF and $5 \mathrm{~mL}$ of peripheral venous blood samples were collected simultaneously for magnesium level analysis. Blood was drawn from the opposite arm to the IV fluid infusion. Magnesium measurements were performed with Roche Hitachi DPP modular system (Roche Modular DPP, Hitachi Ltd., Tokyo, Japan). Normal ranges of serum and CSF magnesium are given as 0.7-1.1 and 1-1.35 mmol/L, respectively (14). After CSF sampling, $9 \mathrm{mg}$ hyperbaric bupivacaine (Marcaine Spinal Heavy, Kırklareli, Turkey) and $20 \mu \mathrm{g}$ fentanyl (Fentanyl, Jannsen Pharmaceutica N.V., Belgium) solution were injected intrathecally. Patients were then placed $10^{\circ}$ Trendelenburg position with left lateral tilt.

Sensory block was assessed every 30 seconds at the midclavicular line by using loss of cold sensation to ice. Onset of T4 sensory block was defined as the time to loss of cold sensation at the T4 level after intrathecal injection following which the operating table was placed horizontally. Sensory block assessment continued repetitively every 2 minutes, until the block was fixed at the same level on three consecutive assessments. The highest achieved level was defined as the maximum sensory block level. Surgery was allowed to start when pinprick sensation at T4 level was lost. Motor block level was assessed and recorded before surgical incision and at the end of surgery with 10 minute intervals using the modified Bromage scale $(0=$ no motor block with free movement of lower extremities, $1=$ hip flexion blocked, $2=$ hip and knee flexion blocked, $3=$ hip, knee and ankle flexion blocked). Onset of T4 sensory block, maximum sensory block level, motor block level and the time to recovery of motor block were recorded. Time to recovery of motor block was defined as the time interval between intrathecal injection and free movement of the lower extremities. First analgesic request, which was recorded as the primary outcome, was defined as the time period between intrathecal injection and the first occasion when the parturient requested analgesics in the postoperative period. After IV infusion of $1 \mathrm{~g}$ paracetamol, patients were transferred to the labour unit for further observation and treatment.

Non-invasive blood pressure and heart rate (HR) were observed at baseline and at 2 minute intervals following spinal injection for the first 15 minutes and at 5 minute intervals throughout the rest of surgery. Baseline, highest and lowest values of systolic blood pressure (SBP) and HR were noted. Hypotension was defined as a decrease of SBP $>30 \%$ of baseline or $<90 \mathrm{mmHg}$ after spinal injection. Hypotensive episodes were treated with an increased rate of crystalloid infusion. If hypotension persisted in the second consecutive measurement, a bolus of ephedrine $5 \mathrm{mg}$ was administered. Bradycardia was defined as a heart rate (HR) of less than 60 beats per minute (bpm) and was planned to be treated with a $0.5 \mathrm{mg}$ atropine bolus. The number of hypotensive episodes, total amount of fluids administered, median ephedrine consumption and number of patients requiring ephedrine in the operating room until the end of surgery were recorded. The incidence of side effects including shivering, nausea, vomiting and pruritus throughout the study period were noted.

There is no comparable study in the literature to provide a reference for sample size calculation. We assumed that a minimum difference that would be clinically important would be $60 \mathrm{~min}$ between the groups. Studies on the effect of IV or neuraxially applied magnesium on spinal anaesthesia reported a wide range of variance for time to first analgesic request (Apan et al. (3), Unlugenc et al. (15), Yousef et al. (16) and Malleeswaran et al. (17) reported 154, 33.8, 40 and 11 minutes, respectively, as the standard deviation in their control groups). Therefore, a sample size of 16 patients in each group was calculated to detect a 60 min difference with a standard deviation (SD) of $60 \mathrm{~min}$ 
(approximate arithmetic mean of the previously mentioned studies) between the groups in time to first analgesic request, with an $\alpha$ error of 0.05 and power of $80 \%$; we recruited 22 patients per group. SPSS for Windows 21 (SPSS, Chicago, IL, USA) was used for statistical analysis. Demographic data, gestational weeks, magnesium levels, time intervals for spinal anaesthesia characteristics, total amount of fluid administered, blood pressure and heart rate are given as mean $\pm \mathrm{SD}$ and compared with Student's t test. Block level, Bromage score, frequency of hypotensive episodes, ephedrine requirement are presented as median [minimum-maximum] and analysed using Mann-Whitney U test. Chi-square or Fisher's exact tests were utilised for the number of patients requiring ephedrine and intraoperative side effects and $p<0.05$ was defined as statistical significance.

\section{RESULTS}

One patient in Group $\mathrm{C}$ was excluded because of inaccurate magnesium measurements due to haemolysis in their blood sample. Two patients in Group Mg were excluded due to blood-stained CSF sampling. Surgical anaesthesia was achieved in all patients without any intraoperative analgesic requirement. Demographic data, gestational weeks, serum and CSF magnesium levels are given in Table 1. No statistical difference was noted between the groups in terms of patients' demographics and gestational weeks. Mean duration of $\mathrm{MgSO}_{4}$ infusion in pre-eclamptic patients was $14.9 \pm 1.6 \mathrm{~h}$ with a minimum of 12 and maximum of $20 \mathrm{~h}$. Serum and CSF magnesium levels were significantly higher in Group Mg. Duration of surgery were $34.5 \pm 7.4 \mathrm{~min}$ in Group $\mathrm{C}$ and $39.9 \pm 10 \mathrm{~min}$ in Group $\mathrm{Mg}(\mathrm{p}=0.054)$. None of the patients needed additional intraoperative analgesia.

Block characteristics and side effects are presented in Table 2. Time to loss of cold sensation at T4 level was significantly faster in the pre-eclamptic group compared to control. Median motor block levels were similar in both groups; only two patients of Group C had partial motor block of the lower extremities (Bromage score 2). Time to first analgesic request was statistically longer in Group $\mathrm{Mg}$ compared to Group C, with a mean difference of $108.6 \mathrm{~min}(95 \% \mathrm{CI}=81.6-135.7)$.

Baseline, maximum and minimum SBP and HR values are presented in Figure 1. Haemodynamic data, fluid and ephedrine requirements are shown in Table 3 . Baseline, maximum and minimum SBP values were significantly higher in Group $\mathrm{Mg}$ than in Group C. Fluid consumption was higher in Group C, whereas no significant difference was observed in hypotension incidence.

\section{DISCUSSION}

This study has demonstrated for the first time that IV $\mathrm{MgSO}_{4}$ therapy in pre-eclamptic patients prolonged the time to first
TABLE 1. Demographic data, gestational weeks and magnesium levels in CSF and serum

\begin{tabular}{lccc}
\hline & Group C $(\mathrm{n}=21)$ & Group $\mathrm{Mg}(\mathrm{n}=20)$ & $\mathrm{p}$ \\
\hline Age (years) & $29.2 \pm 5.3$ & $31 \pm 6$ & 0.325 \\
Weight $(\mathrm{kg})$ & $80.9 \pm 14.2$ & $84.2 \pm 15.3$ & 0.472 \\
Height $(\mathrm{cm})$ & $160.8 \pm 3.8$ & $161.9 \pm 4.3$ & 0.374 \\
Gestational weeks & $31.9 \pm 2.9$ & $32.7 \pm 4$ & 0.436 \\
Serum $\mathrm{Mg}(\mathrm{mmol} / \mathrm{L})$ & $0.77 \pm 0.07$ & $2.14 \pm 0.43$ & $<0.001^{*}$ \\
CSF Mg $(\mathrm{mmol} / \mathrm{L})$ & $1.01 \pm 0.06$ & $1.23 \pm 0.08$ & $<0.001^{*}$ \\
\hline CSF: cerebrospinal fluid & & & \\
Data are given as mean \pm SD & & \\
${ }^{*}<0.05$ : statistical significance between the groups & &
\end{tabular}

TABLE 2. Spinal block characteristics and side effects

\begin{tabular}{lccc}
\hline & $\begin{array}{c}\text { Group C } \\
(\mathrm{n}=21)\end{array}$ & $\begin{array}{c}\text { Group Mg } \\
(\mathrm{n}=20)\end{array}$ & $\mathrm{p}$ \\
\hline Onset of T4 sensory block (sec) & $257.1 \pm 77.5$ & $194.5 \pm 80.1$ & $0.015^{*}$ \\
Maximum sensory block level & $\mathrm{T} 3[\mathrm{~T} 2-\mathrm{T} 4]$ & $\mathrm{T} 2.5[\mathrm{~T} 1-\mathrm{T} 4]$ & 0.162 \\
Motor block level" & $3[2-3]$ & $3[3-3]$ & 0.162 \\
Recovery of motor block (min) & $99.1 \pm 22.7$ & $106 \pm 34.5$ & 0.452 \\
First analgesic request (min) & $137.4 \pm 30.5$ & $246.1 \pm 52.8$ & $<0.001^{*}$ \\
Shivering (n) & $5(23.8 \%)$ & $6(30 \%)$ & 0.655 \\
Nausea (n) & $8(38.1 \%)$ & $8(40 \%)$ & 0.901 \\
Vomiting (n) & $2(9.5 \%)$ & $1(5 \%)$ & 1 \\
Pruritus (n) & $7(33.3 \%)$ & $10(50 \%)$ & 0.279 \\
\hline Data are given as mean \pm SD, median $[\mathrm{min}-\mathrm{max}]$, number $(\%)$ & \\
*p $<0.05:$ statistical significance between the groups & & \\
'Evaluated using modified Bromage scale &
\end{tabular}

TABLE 3. Number of hypotensive episodes, fluid and ephedrine requirement and number of patients requiring ephedrine

\begin{tabular}{lccc}
\hline & $\begin{array}{c}\text { Group C } \\
(\mathrm{n}=21)\end{array}$ & $\begin{array}{c}\text { Group Mg } \\
(\mathrm{n}=20)\end{array}$ & $\mathrm{p}$ \\
\hline Number of hypotensive episodes & $2[0-5]$ & $0[0-4]$ & 0.06 \\
Fluid $(\mathrm{mL})$ & $2060 \pm 366$ & $1533 \pm 387<0.001 *$ \\
Ephedrine $(\mathrm{mg})$ & $0[0-25]$ & $0[0-20]$ & 0.203 \\
Number of patients requiring ephedrine & $10(47.6 \%)$ & $5(25 \%)$ & 0.133 \\
\hline Data are given as median [min-max] and number $(\%)$ & & \\
${ }^{*}<0.05$ : statistical significance between the groups & &
\end{tabular}

analgesic request when compared to healthy preterm parturients following spinal anaesthesia with bupivacaine and fentanyl. We also observed that $\mathrm{IV} \mathrm{MgSO}_{4}$ therapy significantly accelerated the onset of sensory block.

Magnesium is a non-competitive NMDA-antagonist and can potentiate opioid activity with central desensitisation (18). There are a few studies which have looked at the analgesic effects of IV magnesium in patients undergoing spinal anaesthesia; however, none of them have included an obstetric population (3-5). In all of these studies, lower doses of $\mathrm{MgSO}_{4}$ (ranging from $1.03 \mathrm{~g}$ to $12.35 \mathrm{~g}$ ) were used and the infusions were started after lumbar puncture. In contrast to these studies (3-5), in our study, pre-eclamptic patients received $\mathrm{MgSO}_{4}$ before spinal anaesthesia and the lowest total dose of magne- 


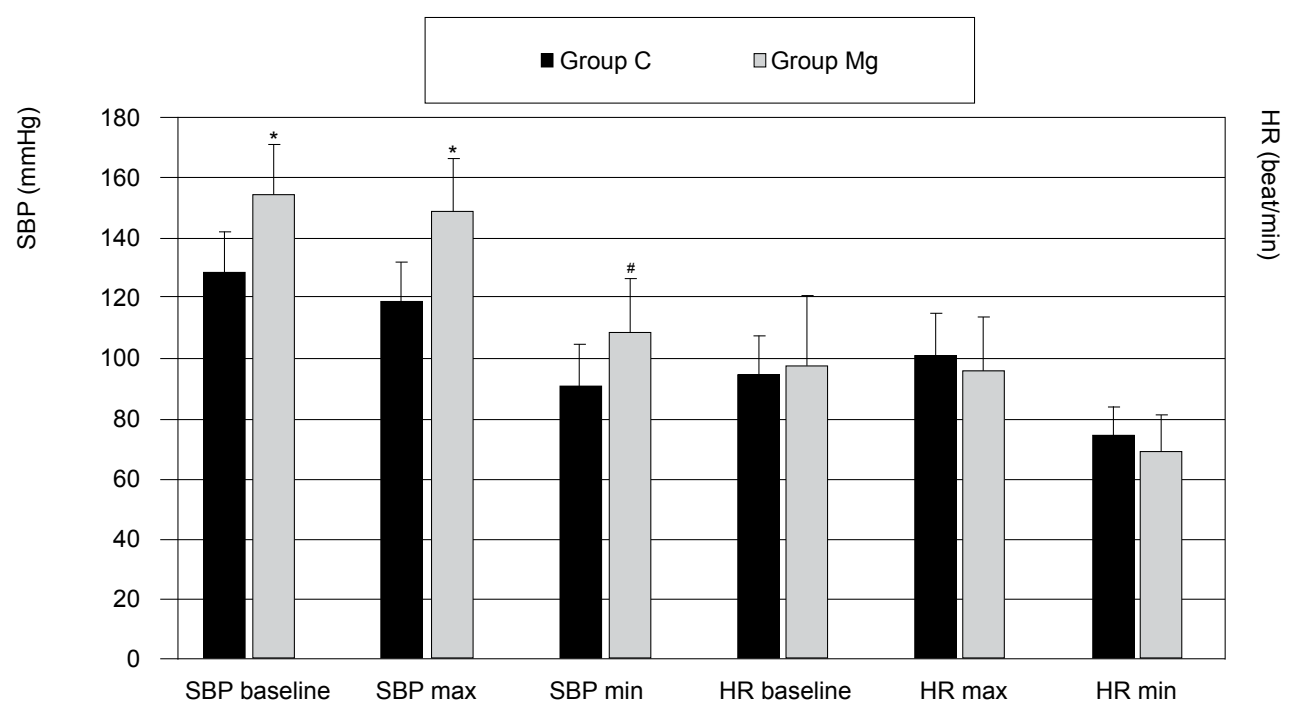

FIG. 1. Systolic blood pressure (SBP) and heart rate (HR) data represent pre-anaesthetic baseline, maximum and minimum values recorded during the study period.

${ }^{*} \mathrm{p}<0.001, \# p=0.001$

sium was $28.5 \mathrm{~g}$ in a patient with the shortest infusion duration of 12 hours.

One major problem with systemic magnesium administration is the bioavailability of magnesium to the central nervous system (CNS). The brain concentration of magnesium, reflected by the CSF magnesium concentration, is tightly controlled in healthy subjects (19) and in disease states such as acute traumatic injury (14). Magnesium has also been applied neuraxially to avoid the poor passage into CNS following systemic administration. Intrathecal and/or epidural magnesium has been shown to be effective as an analgesic adjuvant in obstetric (healthy $(15,16,20)$ and mild pre-eclamptic (17) patients) and non-obstetric populations (1). Of the four obstetric studies, one (16) used combined spinal epidural anaesthesia, whereas three studies $(15,17,20)$ utilised spinal anaesthesia with different intrathecal drug combinations, making the comparison of data difficult.

We observed a faster onset of sensory block in Group $\mathrm{Mg}$ than in Group C. In mild pre-eclamptic patients, Malleeswaran et al. (17) added magnesium to the intrathecal $10 \mathrm{mg}$ bupivacaine- $25 \mu \mathrm{g}$ fentanyl combination and reported a slower onset of sensory and motor block following magnesium compared to the control group. The time difference was roughly one minute and had no clinical significance. Although no significant difference was detected, in their study T4 level was achieved in $70 \%$ and $46.7 \%$ of the patients in the magnesium and control groups, respectively, and T6 level was reported as the maximum sensory level in the rest of the patients. Ghrab et al. (20) observed no differences in onset times of sensory block at the T4 level between the groups with or without intrathecal magnesium. Unlugenc et al. (15) observed a prolongation in sensory block onset by one minute in patients with intrathecal bupivacaine-magnesium combination compared to bupivacaine-fentanyl. None of these obstetric studies explained their findings for sensory block onset and level. Ozalevli et al. (21) studied the effect of intrathecal magnesium added to isobaric bupivacaine-fentanyl combination in orthopaedic surgery patients and also observed a delay in onset of spinal anaesthesia with magnesium. They speculated that the difference in $\mathrm{pH}$ and baricity of the intrathecal drug combination might have contributed to this delay. The shorter onset time in our study is in contrast to their results, which may depend on the anatomical changes of intrathecal space or composition of CSF due to pre-eclampsia.

We did not observe a difference between the groups with regard to recovery of motor block. Malleeswaran et al. (17) found prolonged motor block recovery following intrathecal magnesium in mild pre-eclamptic patients. However, Ozalevli et al. (21) used the same intrathecal drug combination as Malleeswaran et al. (17) and reported no difference in motor block recovery. Sensory block levels achieved in these two studies as well as the patient population may be responsible for their conflicting results.

Our results confirm those of Apan et al. (3), who found a similar duration of motor block but prolonged first analgesic request in their IV magnesium infusion group, with serum 
magnesium levels of $2.53 \pm 0.5 \mathrm{mg} / \mathrm{dL}$ compared to the control group (this roughly correlates to $1.04 \pm 0.21 \mathrm{mmol} / \mathrm{L}$ when converted to SI unit using the conversion factor 0.4114). Interestingly, they did not use opioids in spinal block. Hwang et al. (5) could not detect a difference in the time to first pain following bupivacaine and fentanyl spinal anaesthesia despite a higher serum magnesium level $(1.31 \pm 0.13 \mathrm{mmol} / \mathrm{L})$ compared to Apan et al (3). Although the dose of intrathecal fentanyl was identical to Hwang et al. (5), prolonged spinal analgesia duration in our study is possibly due to the higher serum magnesium levels $(2.14 \pm 0.43 \mathrm{mmol} / \mathrm{L})$.

There are two studies $(7,19)$ that evaluated CSF magnesium levels following IV magnesium administration, only one of which investigated postoperative analgesic consumption. Ko et al. (7) administered magnesium doses that were $50-70 \%$ of the pre-eclampsia treatment for a shorter period of time (6 hours) in non-obstetric patients receiving general anaesthesia. They did not find any difference in postoperative epidural analgesic consumption which they attributed to the similar CSF magnesium levels in their two groups, in spite of high serum magnesium levels $(3.51 \pm 0.42 \mathrm{mg} / \mathrm{dL}$ which roughly correlates to $1.44 \pm 0.17 \mathrm{mmol} / \mathrm{L}$ ) in the magnesium-treated group. However, their results cannot be extrapolated to preeclamptic patients as magnesium transfer to the CSF might differ in pre-eclampsia. One may postulate that pre-eclamptic changes in vascular permeability might allow magnesium to cross the blood brain barrier (8), but there are few reports exploring that theory. In their study comparing CSF magnesium levels in healthy and pre-eclamptic parturients not receiving magnesium therapy, Fong et al. (10) did not find any difference. However, in pre-eclamptic parturients receiving IV magnesium, Thurnau et al. (9) found small but significant increases in CSF magnesium levels. In our study, we also found a significant elevation of CSF magnesium levels in Group $\mathrm{Mg}$ similar to Thurnau et al. (9).

Although not statistically significant, less hypotensive episodes were observed in the pre-eclamptic group, resulting in statistically significant decreased fluid requirements in our study. Aya et al. (22) observed a decreased incidence of hypotension in pre-eclamptic patients compared to preterm nonpre-eclamptic patients. Our control group included preterm parturients similar to Aya et al. (22), meaning that gestational age could match pre-eclamptic parturients.

Regarding sample size, the study can be considered underpowered. Although it is not advised to do so, we performed a post-hoc power analysis (23), where the mean and standard deviation of both groups were used to compute achieved power with given $\alpha$, sample size and effect size (Cohen's $\mathrm{d}=2.5210682$ ); we calculated a power of $99.96 \%$ for our primary outcome ( $G^{*}$ Power software version 3.1.5).

This study inherits the limitations of an observational study. A group of healthy preterm patients receiving the same dose of IV $\mathrm{MgSO}_{4}$ would have given more insight into a relationship between serum/CSF magnesium levels and analgesia duration. However, for ethical reasons, we could not justify such a group of healthy preterm parturients who could suffer possible side effects of preoperative high dose magnesium infusion with no proven benefits. The variable duration and dose of $\mathrm{MgSO}_{4}$ in our study can also be criticised. Due to the nature of the disease, the duration of $\mathrm{MgSO}_{4}$ infusion cannot be standardised in severely pre-eclamptic patients. Although $24 \mathrm{~h}$ $\mathrm{MgSO}_{4}$ therapy is targeted in severely pre-eclamptic patients, obstetric progress is individually assessed and the decision for caesarean section could not be forecasted. Because our institutional protocol for magnesium infusion has an infusion rate of $2 \mathrm{~g} / \mathrm{h}$ versus $1 \mathrm{~g} / \mathrm{h}(24)$, our results may not apply to other institutions. However, similar infusion rates have been reported in the literature $(25,26)$. In addition, working with serum magnesium levels rather than magnesium dose administered could enable this data to be applicable to other magnesium regimens.

In conclusion, our study found that systemic magnesium administration in severely pre-eclamptic parturients prolonged the time to first analgesic request when compared to healthy preterm parturients following spinal anaesthesia with fentanyl and bupivacaine. New studies are needed to clarify the mechanism behind these results and to correlate CSF/serum magnesium levels with postoperative analgesia.

Ethics Committee Approval: Ethics committee approval was received for this study from the Clinical Research Ethics Committee of İstanbul Faculty of Medicine.

Informed Consent: Written informed consent was obtained from patients who participated in this study.

Peer-review: Externally peer-reviewed.

Author contributions: T.Ö.S., O.B., M.O.S., İ.K.; Design - T.Ö.S., O.B., M. O. S. ; Supervision - T.Ö.S., O.B., M.O.S., İ.K.; Resource - T.Ö.S., O.B., İ.K., M.K.; Materials - T.Ö.S., O.B., İ.K.; Data Collection\&/or Processing T.Ö.S., O.B., M.O.S., İ.K.; Analysis\&/or Interpretation - T.Ö.S., M.O.S., İ.K., K.K.; Literature Search - T.Ö.S., M.O.S., İ.K., K.K.; Writing - T.Ö.S., M.O.S., O.B., İ.K.; Critical Reviews - T.Ö.S., M.O.S., O.B., M.K., K.K., İ.K.

Conflict of Interest: No conflict of interest was declared by the authors.

Financial Disclosure: The authors declared that this study has received no financial support.

\section{REFERENCES}

1. Mebazaa MS, Ouerghi S, Frikha N, Moncer K, Mestiri T, James MF, et al. Is magnesium sulfate by the intrathecal route efficient and safe? Ann Fr Anesth Reanim 2011;30:47-50. [CrossRef]

2. Albrecht E, Kirkham KR, Liu SS, Brull R. Peri-operative intravenous administration of magnesium sulphate and postoperative pain: a metaanalysis. Anaesthesia 2013;68:79-90. [CrossRef] 
3. Apan A, Buyukkocak U, Ozcan S, Sari E, Basar H. Postoperative magnesium sulphate infusion reduces analgesic requirements in spinal anaesthesia. Eur J Anaesthesiol 2004;21:766-9. [CrossRef]

4. Dabbagh A, Elyasi H, Razavi SS, Fathi M, Rajaei S. Intravenous magnesium sulfate for post-operative pain in patients undergoing lower limb orthopedic surgery. Acta Anaesthesiol Scand 2009;53:1088-91. [CrossRef]

5. Hwang JY, Na HS, Jeon YT, Ro YJ, Kim CS, Do SH. I.V. infusion of magnesium sulphate during spinal anaesthesia improves postoperative analgesia. Br J Anaesth 2010;104:89-93. [CrossRef]

6. Gupta SD, Mitra K, Mukherjee M, Roy S, Sarkar A, Kundu S, et al. Effect of magnesium infusion on thoracic epidural analgesia. Saudi $J$ Anaesth 2011;5:55-61. [CrossRef]

7. Ko SH, Lim HR, Kim DC, Han YJ, Choe H, Song HS. Magnesium sulfate does not reduce postoperative analgesic requirements. Anesthesiology 2001;95:640-6. [CrossRef]

8. Amburgey O, Chapman AC, May V, Bernstein IM, Cipolla MJ. Plasma from preeclamptic women increases blood-brain barrier permeability: role of vascular endothelial growth factor signaling. Hypertension 2010;56:1003-8. [CrossRef]

9. Thurnau GR, Kemp DB, Jarvis A. Cerebrospinal fluid levels of magnesium in patients with preeclampsia after treatment with intravenous magnesium sulfate: a preliminary report. Am J Obstet Gynecol 1987;157:1435-8. [CrossRef]

10. Fong J, Gurewitsch ED, Volpe L, Wagner WE, Gomillion MC, August P. Baseline serum and cerebrospinal fluid magnesium levels in normal pregnancy and preeclampsia. Obstet Gynecol 1995;85:444-8. [CrossRef]

11. Apostol A, Apostol R, Ali E, Choi A, Ehsuni N, Hu B, et al. Cerebral spinal fluid and serum ionized magnesium and calcium levels in preeclamptic women during administration of magnesium sulfate. Fertil Steril 2010;94:276-82. [CrossRef]

12. Gogarten W. Preeclampsia and anaesthesia. Curr Opin Anaesthesiol 2009;22:347-51. [CrossRef]

13. Lockwood C, Wendel G. ACOG Committee on Practice BulletinsObstetrics. ACOG practice bulletin. Diagnosis and management of preeclampsia and eclampsia. Number 33, January 2002. Obstet Gynecol 2002;99:159-67.

14. McKee JA, Brewer RP, Macy GE, Borel CO, Reynolds JD, Warner DS. Magnesium neuroprotection is limited in humans with acute brain injury. Neurocrit Care 2005;2:342-51. [CrossRef]

15. Unlugenc H, Ozalevli M, Gunduz M, Gunasti S, Urunsak IF, Guler T, et al. Comparison of intrathecal magnesium, fentanyl, or placebo com- bined with bupivacaine $0.5 \%$ for parturients undergoing elective cesarean delivery. Acta Anaesthesiol Scand 2009;53:346-53. [CrossRef]

16. Yousef AA, Amr YM. The effect of adding magnesium sulphate to epidural bupivacaine and fentanyl in elective caesarean section using combined spinal-epidural anaesthesia: a prospective double blind randomised study. Int J Obstet Anesth 2010;19:401-4. [CrossRef]

17. Malleeswaran S, Panda N, Mathew P, Bagga R. A randomised study of magnesium sulphate as an adjuvant to intrathecal bupivacaine in patients with mild preeclampsia undergoing caesarean section. Int J Obstet Anesth 2010;19:161-6. [CrossRef]

18. Herroeder S, Schönherr ME, De Hert SG, Hollmann MW. Magnesium--essentials for anesthesiologists. Anesthesiology 2011;114:971-93. [CrossRef]

19. Mercieri M, De Blasi RA, Palmisani S, Forte S, Cardelli P, Romano R, et al. Changes in cerebrospinal fluid magnesium levels in patients undergoing spinal anaesthesia for hip arthroplasty: does intravenous infusion of magnesium sulphate make any difference? A prospective, randomized, controlled study. Br J Anaesth 2012;109:208-15. [CrossRef]

20. Ghrab BE, Maatoug M, Kallel N, Khemakhem K, Chaari M, Kolsi K, et al. [Does combination of intrathecal magnesium sulfate and morphine improve postcaesarean section analgesia?]. Ann Fr Anesth Reanim 2009;28:454-9. [CrossRef]

21. Ozalevli M, Cetin TO, Unlugenc H, Guler T, Isik G. The effect of adding intrathecal magnesium sulphate to bupivacaine-fentanyl spinal anaesthesia. Acta Anaesthesiol Scand 2005;49:1514-9. [CrossRef]

22. Aya AGM, Vialles N, Tanoubi I, Mangin R, Ferrer JM, Robert C, et al. Spinal anesthesia-induced hypotension: a risk comparison between patients with severe preeclampsia and healthy women undergoing preterm cesarean delivery. Anesth Analg 2005;101:869-75. [CrossRef]

23. Hoenig JM, Heisey DM. The abuse of power: the pervasive fallacy of power calculations for data analysis. Am Stat 2001;55:19-24. [CrossRef]

24. National Institute for Health and Clinical Excellence. Hypertension in pregnancy. The management of hypertensive disorders during pregnancy. NICE clinical guideline (serial online) 107. Issued: August 2010, last modified: January 2011. Available from: http://www.nice.org.uk/ nicemedia/live/13098/50418/50418.pdf

25. Girard B, Beucher G, Muris C, Simonet T, Dreyfus M. [Magnesium sulphate and severe preeclampsia: its use in current practice]. J Gynecol Obstet Biol Reprod 2005;34:17-22. [CrossRef]

26. Belfort MA, Clark SL, Sibai B. Cerebral hemodynamics in preeclampsia: cerebral perfusion and the rationale for an alternative to magnesium sulfate. Obstet Gynecol Surv 2006;61:655-65. [CrossRef] 